\title{
A abordagem da questão do trabalho no campo da Saúde Coletiva com seus limites e desafios: uma revisão narrativa
}

\author{
Abordando el tema del trabajo en el campo de la Salud Colectiva con sus \\ límites y desafíos: una revisión narrativa
}

Approaching the issue of work in the field of Collective Health with its limits and challenges: a narrative review

Recebido: 26 jul 2021

Revisado: 10 ago 2021

Aceito: 17 ago 2021

Autor de correspondência:

Aquilas Mendes

aquilasmendes@gmail.com

Como citar: Cunha FM,

Mendes A. A abordagem da questão do trabalho no campo na Saúde Coletiva com seus limites e desafios: uma revisão narrativa. J Manag Prim Health Care.

2021;13:e010.

https://doi.org/10.14295/jmphc.v13. 1159

Conflito de interesses: Os autores declaram não haver nenhum interesse profissional ou pessoal que possa gerar conflito de interesses em relação a este manuscrito.

Copyright: Este é um artigo de acesso aberto, distribuído sob os termos da Licença Creative Commons (CC-BY-NC). Esta licença permite que outros distribuam, remixem, adaptem e criem a partir do seu trabalho, mesmo para fins comerciais, desde que lhe atribuam o devido crédito pela criação original.

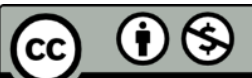

\section{Francisco Mogadouro da CUNHA ${ }^{(1)}$ Áquilas $\operatorname{MENDES}^{(1,2)}$}

\footnotetext{
(1) Universidade de São Paulo - USP, Faculdade de Saúde Pública-FSP, São Paulo, SP, Brasil.

(2) Pontifícia Universidade Católica de São Paulo - PUC-SP, São Paulo, SP, Brasil.
}

\section{Resumo}

Neste estudo, busca-se compreender como o campo científico da Saúde Coletiva vem abordando a questão do trabalho ao longo das décadas de implantação do Sistema Único de Saúde. Realizou-se uma revisão narrativa da literatura sobre a questão do trabalho no campo da Saúde Coletiva. Foram selecionados três periódicos representativos do campo da Saúde Coletiva: Cadernos de Saúde Pública; Ciência \& Saúde Coletiva; e Trabalho, Educação e Saúde. A busca contemplou os artigos cadastrados nas bases de dados Lilacs - Literatura Latino-americana e do Caribe em Ciências da Saúde e Medline - Medical Literature Analysis and Retrieval System Online da BVS. Utilizou-se o item-chave 'Saúde do Trabalhador', incluindo-o para as três revistas. Após o processo de seleção, 34 artigos foram escolhidos e discutidos com base em quatro dimensões de análise: 1) Saúde do Trabalhador: constituição de um campo interdisciplinar; 2) Gênero, trabalho e saúde; 3) Saúde do Trabalhador e Saúde Ambiental; 4) Determinação social ou determinantes sociais da saúde? Utilizou-se como referencial teórico para a análise a perspectiva marxista sobre a centralidade do trabalho. Identificou-se um relevante debate sobre a constituição do campo interdisciplinar denominado Saúde do Trabalhador, mas verificou-se que foi pouco abordada a relação entre ele e o campo mais abrangente da Saúde Coletiva. Considera-se importante afirmar que faltam instrumentos que possam compreender a totalidade heterogênea do mundo do trabalho contemporâneo. $O$ debate sobre a determinação social da saúde aparece pouco nos artigos incluídos na revisão, ao mesmo tempo em que muitos deles adotam o termo determinantes sociais sem maior reflexão. A Saúde Coletiva deixa de reivindicar a centralidade do trabalho quando se afasta da teoria da determinação social da saúde.

Descritores: Saúde do Trabalhador; Saúde Pública; Sistema Único de Saúde; Determinantes Sociais da Saúde. 


\title{
Resumen
}

En este estudio buscamos comprender cómo el campo científico de la Salud Pública ha venido abordando el tema del trabajo a lo largo de las décadas de implementación del Sistema Único de Salud. Una revisión narrativa de la literatura sobre el tema del trabajo en el campo de la Salud Pública se llevó a cabo. Se seleccionaron tres revistas representativas en el campo de la Salud Pública: Cadernos de Saúde Pública; Ciência \& Saúde Coletiva; y Trabalho, Educação e Saúde. La búsqueda incluyó artículos registrados en las bases de datos Lilacs - Literatura latinoamericana y caribeña en ciencias de la salud y Medline - Sistema de análisis y recuperación de literatura médica en línea de la BVS. Se utilizó el elemento clave "Salud del trabajador", incluyéndolo para las tres revistas. Luego del proceso de selección, se eligieron y discutieron 34 artículos en base a cuatro dimensiones de análisis: 1) Salud Ocupacional: constitución de un campo interdisciplinario; 2) Género, trabajo y salud; 3) Salud Ocupacional y Salud Ambiental; 4) ¿Determinación social o determinantes sociales de la salud? La perspectiva marxista sobre la centralidad del trabajo se utilizó como marco teórico para el análisis. Se identificó un debate relevante sobre la constitución del campo interdisciplinario denominado Salud del Trabajador, pero se encontró que apenas se abordó la relación entre éste y el campo más amplio de la Salud Pública. Es importante señalar que faltan instrumentos que permitan comprender la heterogénea totalidad del mundo del trabajo contemporáneo. El debate sobre la determinación social de la salud aparece poco en los artículos incluidos en la revisión, mientras que muchos de ellos adoptan el término determinantes sociales sin mayor reflexión. La salud colectiva no reivindica la centralidad del trabajo cuando se aleja de la teoría de la determinación social de la salud.

Palabras-claves: Salud Laboral; Salud Pública; Sistema Único de Salud; Determinantes Sociales de la Salud.

\begin{abstract}
In this study, we seek to understand how the scientific field of Collective Health has been addressing the issue of work over the decades of implementation of the Unified Health System. A narrative review of the literature on the issue of work in the field of Public Health was carried out. Three representative journals in the field of Public Health were selected: Cadernos de Saúde Pública; Ciência \& Saúde Coletiva; and Trabalho, Educação e Saúde. The search included articles registered in the Lilacs - Latin American and Caribbean Literature on Health Sciences and Medline - Medical Literature Analysis and Retrieval System Online databases of the VHL. The key item 'Worker's Health' was used, including it for the three magazines. After the selection process, 34 articles were chosen and discussed based on four dimensions of analysis: 1) Occupational Health: constitution of an interdisciplinary field; 2) Gender, work and health; 3) Occupational Health and Environmental Health; 4) Social determination or social determinants of health? The Marxist perspective on the centrality of work was used as a theoretical framework for the analysis. It was identified a relevant debate about the constitution of the interdisciplinary field called Worker's Health, but it was found that the relationship between it and the broader field of Public Health was barely addressed. It is important to state that there is a lack of instruments that can understand the heterogeneous totality of the contemporary work world. The debate on the social determination of health appears little in the articles included in the review, while many of them adopt the term social determinants without further reflection. Collective Health fails to claim the centrality of work when it moves away from the theory of the social determination of health. Keywords: Occupational Health; Public Health; Unified Health System; Social Determinants of Health.
\end{abstract}

\section{Introdução}

Parte significativa da população brasileira sofre as consequências do trabalho precarizado e superexplorado, em detrimento de suas condições de vida e de saúde. ${ }^{1,2}$ Ainda que nem todas busquem atendimento no Sistema Único de Saúde - SUS (e que um número menor ainda seja efetivamente atendido), trata-se de uma pressão de demanda que certamente afeta as "portas abertas" do SUS de forma geral. Outra parcela significativa é atendida pelo setor privado, e eventualmente chega ao SUS somente depois de décadas de 
adoecimento e dezenas de tratamentos que na melhor das hipóteses amenizam a dor para permitir que continuem trabalhando nas mesmas condições.

Em contraste com essa demanda, a política de saúde efetivamente existente dá pouca atenção ao sofrimento e ao adoecimento relacionados ao trabalho. Também é quase inexistente a articulação intersetorial, que seria necessária para que o Estado brasileiro interviesse efetivamente nas condições de trabalho insalubres e degradantes, a partir de um diagnóstico epidemiológico da demanda atendida pelo setor saúde. Aliás, o próprio trabalho em saúde no interior do SUS é constrangido pela precarização e pela terceirização 3,4 em suas mais variadas formas - reflexo de problemas estruturais crônicos, como o subfinanciamento, o desfinanciamento e o sucateamento do serviço público. ${ }^{5}$

Para além da limitação da questão do trabalho, enquanto política a ser enfrentada pelo SUS e pelo Estado brasileiro ao longo dos últimos 33 anos de existência desse sistema, é perceptível sua pouca presença no âmbito da análise do campo científico da Saúde Coletiva nesse período.

A Saúde Coletiva brasileira é um campo do conhecimento e âmbito de práticas constituído desde a década de 1970, pela articulação entre a Saúde Pública, a Medicina Preventiva e Social e as Ciências Sociais e Humanas. Trata-se de um campo interdisciplinar e heterogêneo, composto por diferentes áreas temáticas, historicamente articulado com o processo da Reforma Sanitária Brasileira e da constituição do SUS. ${ }^{6-8}$

Vale enfatizar que a questão do trabalho tem pouco espaço não apenas na formação médica (graduação ou residência), mas também em espaços da Saúde Coletiva, como os congressos e seminários da Associação Brasileira de Saúde Coletiva - ABRASCO e do Centro Brasileiro de Estudos de Saúde - CEBES - entidades que reivindicam o movimento da Reforma Sanitária Brasileira.

Um episódio significativo nesse sentido foi quando setores ligados a essas entidades defendiam a proposta de Fundação Estatal de Direito Privado - FEDP como solução para a gestão do trabalho no SUS - uma alternativa que seria "mais pública" do que as quase onipresentes Organizações Sociais - OS. Seus defensores afirmavam reiteradamente que eram assuntos da menor importância questões centrais levantadas pelos trabalhadores que divergiam da proposta: plano de carreira, remuneração, concurso público, estabilidade, tipo de vínculo, unicidade sindical. ${ }^{4}$

Assim, o objetivo deste artigo é compreender como o campo científico da Saúde Coletiva, por meio de sua produção intelectual, vem abordando a questão do trabalho ao longo das décadas de implantação do Sistema Único de Saúde.

A partir desse objetivo algumas perguntas, mais específicas, merecem menção no âmbito da reflexão desse artigo. Como a questão da saúde do trabalhador vem sendo 
ISSN 2179-6750

analisada pela Saúde Coletiva no decorrer da implantação do SUS? É possível verificar uma análise interdisciplinar sobre as questões de gênero, trabalho e saúde e os aspectos da saúde ambiental? Em que medida vem sendo considerado na abordagem do campo da Saúde Coletiva a determinação social da saúde, associada à questão do trabalho?

Ainda, como contexto mais atual, vale registrar que o momento de elaboração do presente artigo coincide com um aumento de intensidade dos ataques contra as políticas sociais e a classe trabalhadora no Brasil, por parte do governo Bolsonaro. ${ }^{9}$

Embora ainda não seja possível dimensionar em sua totalidade os efeitos de medidas como a extinção do Ministério do Trabalho e a asfixia financeira dos sindicatos de trabalhadores, entendemos que essa conjuntura reforça ainda mais a necessidade de se estudar o mundo do trabalho no âmbito da Saúde, especialmente, no contexto da análise do campo da Saúde Coletiva.

Por sua vez, autores recentes como $\operatorname{Dantas}^{10}$ e Silva ${ }^{11}$ retomam o método e as categorias marxistas para avançar no balanço crítico da RSB, da Saúde Coletiva e do SUS, avaliando questões como os dilemas do processo reformista e de suas opções pela via democrática burguesa; o rebaixamento do horizonte estratégico; as privatizações e a contrarreforma do Estado, particularmente no âmbito do trabalho; e a inviabilidade de um Estado Social nos moldes europeus na realidade objetiva brasileira.

É nessa perspectiva de análise que pretendemos seguir, tendo como foco neste estudo a questão do trabalho.

\section{Metodologia}

Trata-se de uma revisão narrativa da literatura sobre a questão do trabalho no campo da Saúde Coletiva. Optamos por realizar a revisão por meio da produção de artigos científicos publicados em principais periódicos do referido campo. Parte-se do referencial teórico marxista e da centralidade do trabalho para estudar como o campo da Saúde Coletiva vêm abordando a questão do trabalho.

Em 2015, um número especial de revista Ciência \& Saúde Coletiva tratou de discutir os principais periódicos do campo da Saúde Coletiva. Parker, ${ }^{12}$ em seu artigo nesse número, enumerou 10 periódicos de Saúde Coletiva indexados no SciELO nos anos 2011, 2012 e 2013. A partir de tal relação, foram selecionados três periódicos, correspondendo a apenas um tipo de classificação Qualis Capes (A2, B1 e B2), respectivamente, sendo: Cadernos de Saúde Pública; Ciência \& Saúde Coletiva; e Trabalho, Educação e Saúde. Considera-se que esses três periódicos são representativos do campo de Saúde Coletiva. 
ISSN 2179-6750

Foi delimitada a busca dos artigos científicos de forma a contemplar as coleções integrais dos três periódicos selecionados: Cadernos de Saúde Pública (desde 1985); Ciência \& Saúde Coletiva (desde 1996); Trabalho, Educação e Saúde (desde 2003).

Tendo em vista os múltiplos sentidos da palavra trabalho - que pode fazer referência ao trabalho em saúde, a um trabalho científico, ao mercado de trabalho ou mesmo ao trabalho de parto -, verificou-se em análise preliminar que não seria adequado utilizá-la para operacionalizar o levantamento dos artigos nos periódicos escolhidos.

No campo da Saúde Coletiva brasileira e latino-americana, o termo 'Saúde do Trabalhador' vem sendo utilizado desde a década de 1970 em contraposição à Medicina do Trabalho e à Saúde Ocupacional. ${ }^{13}$

Atualmente esse termo é utilizado tanto para fazer referência a uma área específica dentro do campo da Saúde Coletiva, como para abordar uma política específica do SUS. ${ }^{14}$

Assim, optou-se por definir Saúde do Trabalhador como item-chave para executar o levantamento nos artigos, na forma que passamos a descrever.

Embora os três periódicos estejam integralmente disponíveis na plataforma Scientific Electronic Library Online - SciELO, considera-se que seu mecanismo de busca não apresenta algumas funções de filtro e exportação que seriam úteis para o presente estudo.

Assim, optou-se por utilizar Biblioteca Virtual em Saúde Pública - BVS, restringindose às bases de dados Lilacs e Medline. A BVS permite a elaboração de um filtro contemplando os três periódicos selecionados em uma única operação, assim como exportar os resultados em uma única planilha.

A busca foi realizada em 13/08/2018, contemplando, portanto, os artigos cadastrados nas bases de dados Lilacs - Literatura Latino-americana e do Caribe em Ciências da Saúde e Medline - Medical Literature Analysis and Retrieval System Online da BVS até tal data. Ao se utilizar as ferramentas da BVS, foi construído o termo de busca correspondente a todos os artigos dos três periódicos. Para tanto, utilizou-se o item-chave 'Saúde do Trabalhador', indicado como 'assunto principal', isto é, "mj", como identificado nas bases. A partir daí, incluiu-se o operador boleano "AND" para cruzar com as Revistas selecionadas, sendo que nas bases de dados se refere a "ta" - Título da Revista, em sua forma abreviada. Então, utilizou-se o operador boleano "OR" para incluir as três revistas. A sintaxe, após essa identificação, está expressa a seguir:

(mj:("saúde do trabalhador")) AND (ta:("Cad Saude Publica" OR "Cien Saude Colet" OR "Trab. educ. saúde")) AND ( db:("MEDLINE" OR "LILACS")) 
ISSN 2179-6750

Com essa sintaxe foi possível obter uma lista de 206 artigos indexados nas bases LILACS e MEDLINE, já eliminadas manualmente as redundâncias entre as duas bases e as entradas que não correspondiam a artigos científicos (editoriais, entrevistas e comentários).

Após leitura de todos os resumos, 16 itens da lista inicial foram excluídos: 12 por não terem relação com o tema, sugerindo uma indexação equivocada, e 4 por tratar somente de experiências em outros países (Chile, Colômbia e México). Assim, foi delimitada uma base de 190 artigos.

Também a partir da leitura de seus resumos, os artigos foram classificados em 4 categorias, de acordo com o tipo de estudo: debate teórico (53), estudo de caso (65), estudo epidemiológico (67), revisão de literatura médica (5).

Quando o resumo deixou dúvida sobre o tipo de estudo, foi realizada a leitura integral do artigo para verificar a categoria mais precisa. Os artigos que poderiam ser classificados em mais de uma categoria (por exemplo: estudo epidemiológico associado a debate teórico) foram classificados de acordo com a categoria predominante.

De acordo com o objetivo da presente revisão de focar na questão do trabalho, foram selecionados para leitura integral os 53 artigos classificados na categoria debate teórico, publicados entre 1990 e 2016 pelos três periódicos, sendo: 27 por Ciência e Saúde Coletiva,

\section{4 por Cadernos de Saúde Pública e 2 por Trabalho, Educação e Saúde.}

Foi realizada a leitura sistemática dos artigos incluídos (53), seguindo a ordem cronológica de publicação, de forma a identificar as principais questões abordadas e os referenciais teóricos.

Para efeito da presente revisão - a questão do trabalho na produção científica da saúde coletiva - foram destacados 34 artigos. Os 19 artigos restantes ficaram para ser abordados em uma revisão específica de políticas públicas e de legislação, dando origem a abordagem da questão do trabalho e o Sistema Único de Saúde, que será tratada em outro artigo.

\section{Resultados}

Para a apresentação dos resultados dos 34 artigos incluídos nesta revisão, sintetizamos os seus principais argumentos em quatro dimensões: 1) Saúde do Trabalhador: constituição de um campo interdisciplinar; 2) Gênero, trabalho e saúde; 3) Saúde do Trabalhador e Saúde Ambiental; 4) Determinação social ou determinantes sociais da saúde?

\section{Saúde do Trabalhador: constituição de um campo interdisciplinar}

Segundo Deppe, ${ }^{15}$ a Medicina do Trabalho é formada por três campos: patologia do trabalho, fisiologia do trabalho e toxicologia do trabalho. Ligada à clínica médica, a 
patologia do trabalho atua no final da evolução de uma doença, e busca identificar uma causa específica para o dano causado. A fisiologia do trabalho, relacionada à engenharia e à ergonomia, estuda o trabalho em situações de laboratório isoladas, e se ocupa basicamente da capacidade da força de trabalho humana. Já a toxicologia do trabalho estuda as atividades biológicas das substâncias no organismo humano, com ênfase nos valores máximos toleráveis de cada substância nos postos de trabalho.

Para o autor, esses três campos utilizam somente métodos das ciências naturais, que analisam os órgãos humanos de forma isolada e dissociada uns dos outros, ou no máximo como indivíduo biológico abstrato. Assim, negligenciam aspectos sociais e psíquicos. Além disso, atuam em perspectiva monocausal (uma carga específica é considerada a causa de distúrbios específicos de saúde), o que raramente ocorre na realidade do trabalho.

Nesse sentido, Deppe destaca a relevância das cargas psicossociais decorrentes da organização do trabalho nos dias atuais, e aborda a questão dos distúrbios de bem-estar relatados em certas atividades profissionais: pessoas que se sentem mal subjetivamente, com queixas inespecíficas como mudanças de paladar, falta de apetite, vertigem, dor de cabeça, cansaço, insônia, sentimento de intranquilidade.

Embora essas pessoas sejam geralmente consideradas saudáveis por exames médicos, o autor defende que os sintomas inespecíficos podem ser considerados sensores das cargas presentes nas empresas, pois permitem detectar o adoecimento relacionado ao trabalho em uma fase inicial. Para isso, é necessário superar a prática médica reducionista e focada somente nas ciências naturais.

Minayo-Gomez e Thedim-Costa ${ }^{16}$ retomam a crítica à Medicina do Trabalho, caracterizando sua prática: "sob uma visão eminentemente biológica e individual, no espaço restrito da fábrica, numa relação unívoca e unicausal, buscam-se as causas das doenças e acidentes". ${ }^{16,}$ p. 22 Para eles, mesmo a atuação do Estado no espaço do trabalho foi constituída historicamente a partir dessa concepção dominante.

Os autores relatam o surgimento da Saúde Ocupacional que avança com relação à Medicina do Trabalho por sua perspectiva interdisciplinar e multicausal: um conjunto de fatores é levado em conta na produção da doença. Esse avanço é limitado quando os agentes/riscos são descontextualizados de seu caráter social: as medidas prescritas acabam por restringir-se a intervenções pontuais sobre os riscos mais evidentes, com ênfase nos equipamentos de proteção individual e na imputação aos trabalhadores do ônus por acidentes e doenças.

No mesmo sentido, Lacaz $^{17}$ ressalta que para a Saúde Ocupacional "o trabalho é apreendido pelas características empiricamente detectáveis mediante instrumentos das 
ISSN 2179-6750

ciências físicas e biológicas[, e que sua intervenção busca] adaptar ambiente e condições de trabalho a parâmetros preconizados para a média dos trabalhadores normais". ${ }^{17, \text { p. } 759}$

Ao contrário da Medicina do Trabalho e da Saúde Ocupacional, o campo da Saúde do Trabalhador tem como pilar fundamental "o compromisso com a mudança do intrincado quadro de saúde da população trabalhadora". ${ }^{16, ~ p . ~} 24$ Trata-se de um corpo de práticas teóricas interdisciplinares e interinstitucionais, com uma perspectiva comum, resultante de um acúmulo no âmbito da Saúde Coletiva, da Medicina Social latino-americana e com forte influência da experiência italiana.

Ainda segundo Minayo-Gomez e Thedim-Costa, ${ }^{16}$ é relevante para o campo da Saúde do Trabalhador a contribuição das Ciências Sociais, particularmente da teoria marxista. Os autores fazem referência ao conceito de processo de trabalho, que para eles expressa o conflito entre capital e trabalho e se manifesta historicamente através das diversas formas de controle da produção (taylorismo, fordismo, neotaylorismo, pós-fordismo, toyotismo).

Lacaz $^{17}$ entra em maiores detalhes quanto ao processo de trabalho: citando Marx, afirma que o trabalho é ação do homem sobre a natureza para modificá-la e transformá-la e a si mesmo. O autor apresenta também as categorias objeto de trabalho e instrumentos de trabalho segundo a leitura marxista.

Minayo-Gomez e Thedim-Costa ${ }^{16}$ também caracterizam o campo da Saúde do Trabalhador como interdisciplinar e multiprofissional por natureza, uma vez que a complexidade dos processos de trabalho não pode ser contemplada em sua abrangência por nenhuma disciplina isolada. Nesse sentido, os autores citam a Clínica, a Engenharia, a Toxicologia, a Ergonomia, a Epidemiologia e as Ciências Sociais e Humanas, e apresentam algumas noções advindas dessa interação: penosidade, carga de trabalho, exigências, desgaste - este último formulado por Laurell e Noriega. ${ }^{18}$

A questão da integração entre disciplinas na Saúde do Trabalhador é analisada por Porto e Almeida. ${ }^{19}$ Os autores descrevem a disciplinaridade restrita que caracterizou o nascimento da ciência moderna e apresentam diferentes estratégias de superação: a multi, a inter e a transdisciplinaridade.

A multidisciplinaridade seria o simples agrupamento de disciplinas em torno de um dado tema; a interdisciplinaridade envolveria uma maior articulação entre as disciplinas, com ou sem a preponderância de uma delas; já a transdisciplinaridade consistiria na radicalização da interdisciplinaridade, articulando disciplinas em torno de um campo teórico e operacional particular.

A partir desse referencial, os autores analisam a inserção acadêmica da Saúde do Trabalhador no campo mais abrangente da Saúde Coletiva. Para eles, a Saúde do Trabalhador chegou a se configurar de forma mais orgânica como espaço institucional e 
ISSN 2179-6750

operativo do SUS do que como área acadêmica com arcabouço conceitual e metodológico próprios dentro da Saúde Coletiva. Eles destacam a forte imbricação entre investigação e intervenção na área, assim como uma certa indisciplinaridade metodológica, combinada com "doses de militância, voluntarismo e rebeldia que caracterizam a área". 19, p. 343

Um artigo mais recente de Minayo-Gomez e Thedim-Costa ${ }^{20}$ sobre a influência das Ciências Sociais no campo conclui que nas duas últimas décadas vem ocorrendo "um distanciamento das explicações globalizantes, das macroteorias e das metanarrativas", ao mesmo tempo em que prevalecem "explicações de médio alcance que contemplam diversidades de mediações, temporalidades diferentes [...] e especificidades tanto das questões como dos sujeitos sociais estudados". 20, p. 134 Os autores refutam as críticas quanto ao caráter fragmentado e pós-moderno desses estudos, afirmando que são abordagens complementares e não excludentes.

Já o artigo de Minayo-Gomez e Lacaz ${ }^{21}$ critica de forma mais contundente a produção científica da Saúde do Trabalhador, entendendo que existe um "encolhimento da reflexão e do empenho individual e coletivo para construir instrumentos que deem conta da totalidade heterogênea que configura hoje o universo dos trabalhadores brasileiros". 21, p. 800

A partir de extenso levantamento realizado por Mendes $^{22}$, os autores entendem que a produção científica tem enfatizado problemas de saúde dos trabalhadores industriais, com abordagens próximas às da Medicina do Trabalho; mais recentemente aparecem pesquisas sobre o setor de serviços, mas são poucas as teses que "focalizam problemas gerais da área, temáticas referentes à política, modelos e serviços de atenção à saúde do trabalhador e aos processos de vigilância". 21, p. 802

Em síntese, os autores consideram que predomina a construção de conhecimento "fragmentado, disperso, unidisciplinar, quando não repetitivo e tecnicista, resultante de pesquisas e análises pontuais desenvolvidas com abordagens próprias de cada disciplina". 21,p. 802

Assim, eles apontam que existe uma crise do pensamento intelectual no campo, ao mesmo tempo em que a decadência de representatividade dos sindicatos faz com que grande parte dos trabalhadores (inclusive os desempregados) não têm suas demandas formuladas e organizadas coletivamente.

Além da atuação interdisciplinar e multiprofissional, uma premissa metodológica fundamental da Saúde do Trabalhador é a interlocução com os próprios trabalhadores, "depositários de um saber emanado da experiência e sujeitos essenciais quando se visa uma ação transformadora". ${ }^{16,}$ p. 29

Nesse sentido, os autores dialogam com um princípio central do Modelo Operário Italiano: a não-delegação, expressa quando os próprios trabalhadores sistematizam e 
validam o conhecimento obtido por grupos submetidos às mesmas condições de trabalho, em vez de delegar essa atribuição a técnicos ou dirigentes sindicais.

O mesmo princípio é abordado por Sato, ${ }^{23}$ ao analisar as possibilidades de levar em conta o conhecimento prático dos trabalhadores nas ações de Vigilância em Saúde do Trabalhador. Em outro artigo, a autora estuda o replanejamento do trabalho por meio de micronegociações cotidianas protagonizadas por trabalhadores comuns, de forma independente da ação política coletiva. ${ }^{24}$

Sato ${ }^{25}$ também contribui para o debate sobre a constituição do campo ao tratar das Lesões por Esforços Repetitivos - LER, entendidas por ela não somente como objeto de estudo do campo da Saúde do Trabalhador, mas também como pretexto para o avanço de sua construção.

Nesse sentido, a autora chama atenção para alguns atributos peculiares das LER, além de sua importância quantitativa: diferentemente das doenças profissionais, elas não respeitam fronteiras entre categorias profissionais; seu diagnóstico é clínico, baseado principalmente nos sintomas do trabalhador; são preveníveis e potencialmente incapacitantes; têm forte associação com sofrimento psíquico.

Sato e Bernardo ${ }^{26}$ apresentam a questão da Saúde Mental e Trabalho como uma verdadeira subárea dentro do campo da Saúde do Trabalhador, conformada por estudos, pesquisas intervenções no Brasil desde a década de 1980.

Para as autoras, a Saúde Mental e Trabalho passa a considerar as relações de trabalho e sua historicidade como matriz de leitura, em coerência com as formulações da Saúde Coletiva. Ainda assim, é constante o enfrentamento com a lógica positivista, que prevalece fortemente nos campos previdenciário e judicial, para a qual os problemas psíquicos dos trabalhadores têm sua gênese no universo intra-individual.

As autoras propõem uma taxonomia com cinco grupos de problemas que conformam essa subárea: (1) a relação entre saúde mental e organização do processo de trabalho; (2) os efeitos neuropsicológicos decorrentes da exposição a solventes e metais pesados; (3) as repercussões psicossociais decorrentes de acidentes e doenças do trabalho, em que as LER são um relevante exemplo; (4) o sofrimento psíquico dos trabalhadores que enfrentam cotidianamente situações de risco à vida; (5) o desemprego prolongado e suas repercussões.

Ao analisarem dados do Centro de Referência em Saúde do Trabalhador - CRST de Campinas - SP, Sato e Bernardo ${ }^{26}$ constatam que o número de notificações de problemas de saúde mental relacionados ao trabalho ainda é pouco significativo em relação ao número de atendimentos, mas que vem aumentando a lista de ocupações entre aquelas que frequentemente apresentam esses problemas. 
As autoras entendem que a relativa baixa prevalência desses diagnósticos não indica necessariamente uma baixa frequência na população trabalhadora - e sim uma dificuldade generalizada em reconhecer o trabalho como causador de problemas de saúde mental, inclusive por parte dos próprios trabalhadores.

No mesmo sentido, Leão e Minayo-Gomez ${ }^{27}$ afirmam que os processos de patologização e medicalização prevalecem "nesse tempo marcado pela intolerância com o sofrimento e exigência de permanente bem-estar", em que "os próprios sujeitos acabam sendo socialmente conduzidos a medicalizar sua dor". Afinal, "por influência do pensamento cartesiano, emergiu a noção da mente como espécie de vida interior, distinta dos eventos externos aos sujeitos". ${ }^{27, \text { p. } 4651}$

Já Brant e Minayo-Gomez ${ }^{28}$ abordam o processo de transformação do sofrimento em adoecimento, contemplando a medicalização e a psiquiatrização de questões que são sociais e coletivas. Os autores apontam a relação entre esses processos e o mundo do trabalho contemporâneo, em que "parece não haver lugar para o sofrimento, [...] visto como sinal de fraqueza". ${ }^{28,}$ p. 222

Por outro lado, Sato e Bernardo ${ }^{26}$ afirmam que a ocorrência de sintomas físicos de LER parece autorizar o trabalhador a apresentar queixas relacionadas à saúde mental quando procuram o CRST, e que essas queixas muitas vezes antecedem a ocorrência dos problemas osteomusculares. São comuns expressões como ritmo alucinante, trabalho incessante, loucura e desespero para descrever seu sofrimento diante das características de organização do trabalho, que é ao mesmo tempo físico e psíquico.

As autoras relacionam esses problemas às profundas mudanças no mundo do trabalho nas últimas décadas, às altas taxas de desemprego e ao discurso da competência, que deposita no indivíduo a causa de todos os males. Da mesma forma, o enfraquecimento da mobilização dos trabalhadores em tempos de hegemonia neoliberal tem reflexo direto na sua capacidade de enfrentamento coletivo dos problemas que afetam sua saúde mental.

Para enfrentar as questões de saúde mental na perspectiva da Vigilância em Saúde do Trabalhador, Leão e Minayo-Gomez ${ }^{27}$ afirmam que se faz necessário desnaturalizar a organização do trabalho, realizando análise criteriosa que englobe a observação das relações e do cotidiano do trabalho. Os autores propõem oito eixos que devem ser estudados: (i) organização do tempo e intensidade da produção; (ii) práticas de gestão; (iii) cultura organizacional; (iv) relações interpessoais; (v) atividade e autonomia; (vi) relação dos sujeitos com sua atividade; (vii) situações relativas ao vínculo de trabalho; (viii) questões externas ao processo de trabalho.

Freire $^{29}$ apresenta especificamente o tema do assédio moral: trata-se de uma espécie de violência cotidiana, reiterada e dissimulada, com grande impacto para a saúde mental 
ISSN 2179-6750

dos trabalhadores - ainda que de difícil mensuração. A autora propõe que tanto os empregadores quanto o poder público criem medidas preventivas e de fiscalização para evitar a ocorrência do assédio moral.

Por fim, o artigo de Ramminger, Athayde e Brito ${ }^{30}$ apresenta cinco diferentes abordagens metodológicas que podem contribuir para os estudos em Saúde do Trabalhador: (i) a Enquete Operária de Marx, que tem como objetivo não somente obter dados, mas também provocar a reflexão crítica dos trabalhadores sobre as relações de exploração e sua superação; (ii) a Análise Ergonômica do Trabalho, cuja linha francófona prioriza a análise da situação concreta de trabalho, com ênfase na diferença entre trabalho prescrito e trabalho real - enquanto a linha estadunidense e britânica enfatiza a adaptação dos dispositivos tecnológicos às características e limites dos seres humanos; (iii) a Psicodinâmica do Trabalho, que complementa a contribuição da Ergonomia da Atividade ao enfatizar a mobilização subjetiva do trabalhador, que usa sua inteligência para suprir o hiato entre trabalho prescrito e trabalho real; (iv) o Modelo Operário Italiano e a Comunidade Científica Ampliada, centrado na valorização da experiência dos trabalhadores, em diálogo com os saberes científicos; (v) o paradigma ergológico, com o Dispositivo Dinâmico de Três Polos, que articula os saberes organizados das ciências, os saberes investidos na atividade e as exigências éticas e epistemológicas.

\section{Gênero, trabalho e saúde}

No material estudado, a relação entre as questões de gênero e a Saúde do Trabalhador aparece pela primeira vez em artigo de Brito e D'Acri. ${ }^{31}$ As autoras analisam a constituição histórica da divisão sexual do trabalho no capitalismo, apontando o papel do patriarcalismo nesse processo.

Para elas, é da relação patriarcal - que atribui uma posição superior aos homens e inferior às mulheres - que surgem os papéis do homem como principal provedor e da mulher como trabalhadora complementar, cuja responsabilidade principal no capitalismo está ligada à reprodução da força de trabalho. Essa categoria compreende não apenas a procriação, mas também o trabalho doméstico.

As autoras ainda comparam a divisão sexual do trabalho - que distribui entre os gêneros atividades desiguais, umas mais ligadas à produção e outras à reprodução social à divisão social do trabalho no capitalismo, que opõe proprietários e não-proprietários dos meios de produção. Assim como ocorre na divisão social do trabalho, o carácter histórico da divisão sexual do trabalho é ocultado por uma operação ideológica, que atribui às diferenças biológicas o caráter natural dessa diferenciação. 
ISSN 2179-6750

Ainda segundo Brito e $D^{\prime}$ Acri, ${ }^{31}$ a relação de gênero também se manifesta no mundo do trabalho fora do domicílio: as mulheres tendem a ser alocadas em postos de trabalho que apresentam exigências próximas às do trabalho doméstico, como a destreza manual, a monotonia e a atenção a vários sinais. Assim, o falso entendimento de que essas habilidades são competências naturais (e não historicamente construídas) das mulheres contribui para desvalorizar o trabalho feminino e para mascarar o desgaste causado por esses postos de trabalho.

Já Aquino, Menezes e Marinho ${ }^{32}$ chama a atenção para o desconhecimento generalizado sobre os efeitos do trabalho para a saúde das mulheres no Brasil e no mundo. As autoras atribuem esse desconhecimento a dois fatores: a invisibilidade do trabalho feminino e a visão restrita da medicina moderna sobre as mulheres.

O primeiro fator é caracterizado pela ausência quase total de estudos científicos sobre atividades laborais historicamente exercidas por mulheres. As autoras destacam o exemplo do trabalho noturno hospitalar - que, apesar de ser uma das formas mais antigas de organização do trabalho, quase não aparece nos estudos científicos sobre as consequências do trabalho em turnos. Afinal, esses estudos priorizam o trabalho industrial, majoritariamente masculino.

Já o segundo fator tem relação com a ênfase dada pela medicina ao papel da mulher essencialmente como mãe, em detrimento dos demais aspectos de sua vida. Essa visão restrita orientou quase toda a produção científica para os aspectos relacionados à saúde do feto, e não da mulher - vista apenas como grávida ou potencialmente grávida.

Ao se buscar contribuir para a superação desse desconhecimento que marca a questão do trabalho feminino e seus impactos para a saúde, Aquino, Menezes e Marinho ${ }^{32}$ descrevem o processo histórico de participação das mulheres no mercado de trabalho brasileiro - marcado por períodos de fluxo e refluxo de acordo com as necessidades do capital - e caracterizam o período atual, em que houve expressivo aumento dessa inserção, inclusive em postos de trabalho antes tidos como masculinos.

Para além das questões relacionadas aos postos e processos de trabalho, as autoras apontam também outros problemas que acometem especificamente as mulheres: as relações de dominação patriarcal se reproduzem em todas as esferas da vida, inclusive no trabalho. Assim, as mulheres trabalhadoras estão sujeitas não somente às relações de opressão comuns a todos os trabalhadores, mas também a violências específicas como assédio sexual, práticas de controle da reprodução (exemplo: vistoria de absorventes), testes de gravidez nos exames ocupacionais e revistas constrangedoras na saída das fábricas.

A seguir, Aquino, Menezes e Marinho ${ }^{32}$ tratam da divisão sexual do trabalho e de suas consequências para o sofrimento mental: educadas desde a infância para seu papel na 
ISSN 2179-6750

reprodução social, as mulheres desenvolvem qualidades pretensamente naturais (docilidade, paciência, resistência para o trabalho monótono e repetitivo) de grande utilidade para o capital. O desgaste psíquico causado no exercício de tais qualidades é potencializado pelos efeitos do trabalho doméstico (uma segunda jornada de trabalho), assim como pelo próprio esforço de conciliação dos dois trabalhos.

As autoras concluem afirmando que é necessário intensificar o ainda incipiente diálogo entre saúde ocupacional e sociologia do trabalho, apontando que as reflexões feministas têm possibilitado compreender questões como a maior fragilidade das mulheres nos enfrentamentos capital-trabalho. Um exemplo é a baixa taxa de sindicalização das mulheres, bem vista por uma parcela do empresariado - que justifica sua preferência por contratar mulheres por sua docilidade e submissão.

No mesmo sentido, Brito ${ }^{33}$ apresenta uma proposta de Vigilância em Saúde do Trabalhador que incorpora o olhar de gênero: partindo do pressuposto de que o questionamento da divisão sexual do trabalho interessa a todos os trabalhadores e não ao capital, a autora propõe incorporar as desigualdades entre homens e mulheres em instrumentos de vigilância, como os mapas de risco.

Brito $^{33}$ conclui apontando a questão das diferenças como ponto de vista indispensável para enriquecer a abordagem latino-americana da Saúde do Trabalhador, "reafirmando a centralidade da categoria trabalho, na sua acepção ampliada, mas também assumindo a centralidade das relações intersubjetivas, que foi apontada dentro da

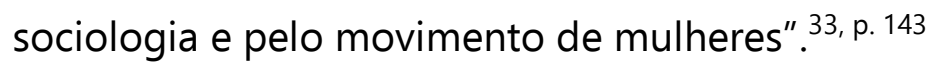

Em outro artigo, Brito ${ }^{34}$ analisa os impactos para a saúde dos processos de reestruturação produtiva e precarização do trabalho, tomando como eixo a divisão sexual do trabalho e as relações de gênero.

A autora descreve a tendência mundial de incorporação das mulheres no mercado de trabalho, apontando que esse processo busca minimizar os custos de produção e é acompanhado de acirramento das diferenças entre situações de trabalho masculinas e femininas. Nesse sentido, as mulheres são mais vulneráveis à precarização do trabalho, tanto no setor informal quanto por meio de contratos temporários ou outros regimes atípicos.

Brito $^{34}$ relata que a questão de gênero está articulada com o movimento do capital para tirar vantagem dos baixos salários e da fraca regulamentação trabalhista nos países do Terceiro Mundo: quando se movimenta nesse sentido, há a tendência de as mulheres serem a força de trabalho preferida.

Para a autora, as consequências desses processos para a saúde das trabalhadoras são insidiosas, muitas vezes inespecíficas e não indenizáveis; as mulheres estão nos ângulos 
mortos do sistema previdenciário, acumulando agravos não específicos e para os quais não há normas apropriadas.

Da mesma forma, as mulheres trabalhadoras estão mais sujeitas a lesões por esforços repetitivos, a problemas psicossomáticos e às consequências do isolamento social decorrente do teletrabalho - amplamente feminizado por ser supostamente conciliável com o trabalho doméstico.

Ainda segundo Brito, $^{34}$ o trabalho das mulheres sempre esteve associado à precariedade: mesmo quando a insegurança, a instabilidade e o desemprego atingem toda a população trabalhadora, o trabalho masculino tende a estabilizar-se mais que o feminino.

Afinal, segundo a autora, com a precarização do trabalho que acompanha a globalização, as mulheres encontram-se nas situações vulneráveis: estão mais sujeitas a enfraquecimento e perda de direitos e a modalidades como o trabalho a domicílio, a terceirização, o trabalho em tempo parcial, o trabalho informal, os contratos temporários e o trabalho sazonal.

Por fim, Brito ${ }^{35}$ retoma o debate sobre a divisão sexual do trabalho, afirmando que essa questão deve ser levada em conta em toda análise e intervenção sobre saúde do trabalhador. Além disso, argumenta que mesmo nas pesquisas sobre violência doméstica deve-se levar em conta a divisão sexual do trabalho - afinal o domicílio também é um local de trabalho. Para a autora, essa seria "mais uma indicação da capacidade contida no campo da Saúde do Trabalhador no sentido de interpelar toda a área da Saúde Coletiva". ${ }^{35, ~ p . ~} 887$

\section{Saúde do Trabalhador e Saúde Ambiental}

Nos artigos científicos estudados, aparece com grande frequência o debate sobre a necessidade de se pensar os impactos dos processos produtivos para a saúde de quem trabalha de forma articulada com as consequências desses processos para o meio ambiente.

Assim, Franco e Druck ${ }^{36}$ apontam para a necessidade de se abordar "a relação entre trabalho, saúde e meio ambiente em sua dupla dimensão: dentro e fora das plantas industriais". ${ }^{36, \text { p. }} 62$ No mesmo sentido, Porto e Freitas ${ }^{37}$ apresentam o conceito de riscos tecnológicos ambientais para contemplar as diversas dimensões da tecnologia (técnica, cognitiva, social, cultural e filosófica) e seu impacto para além dos locais de trabalho.

Para Franco e Druck, ${ }^{36}$ as condições objetivas e subjetivas da saúde humana e da sustentabilidade ambiental vêm sofrendo profundas transformações desde a Revolução Industrial. Esse processo contempla desde as relações existentes entre os homens, quando à propriedade dos meios de produção e dos produtos do trabalho, até questões ambientais como o uso de novas fontes de energia e demais recursos naturais, assim como a geração de quantidades crescentes de resíduos industriais. 
ISSN 2179-6750

As autoras afirmam que essas transformações são dirigidas por uma racionalidade econômica subordinada à lógica do lucro, da acumulação e do retorno do capital investido. Assim, ocorre uma progressiva concentração de capital, levando a uma globalização desigual e excludente.

Ao mesmo tempo, os últimos séculos têm sido marcados por um notável desenvolvimento tecnológico, com crescente mecanização e automatização do processo de trabalho. Apesar disso, as autoras entendem que esses avanços não necessariamente contribuem para reverter o processo de organização taylorista do trabalho, com suas diversas formas de agressão aos indivíduos.

Além do processo já existente de busca por recursos naturais e menores custos de mão de obra, Franco e Druck $^{36}$ apontam para um novo movimento do capital nas últimas décadas: a busca por países mais permissivos em termos de direitos trabalhistas e ambientais - geralmente os mais periféricos. Em paralelo, ocorrem pressões para a reversão dos avanços sociais nos países centrais.

Porto $^{38}$ explica esse movimento usando o termo chantagem locacional, cunhado por Henri Acselrad: "o capital negocia seus investimentos nas áreas onde não somente são oferecidas as maiores taxas de lucros, mas as menores resistências sociais e políticas voltadas ao controle da poluição e das injustiças sociais." ${ }^{38, ~ p . ~} 837$

Em conjunto com a reestruturação produtiva e com as medidas econômicas neoliberais, ocorre assim um "fenômeno novo historicamente, que é o descolamento entre crescimento econômico e o emprego". ${ }^{36, ~ p . ~} 64$ Portanto, mesmo nos países centrais (e mais ainda nos periféricos) ocorre uma destruição de empregos com direitos trabalhistas assegurados, substituídos por situações de trabalho precário.

Segundo as autoras, o agravamento da exclusão social que decorre desse processo acontece ao mesmo tempo que a humanidade interfere profundamente nos mecanismos reguladores da biosfera, causando destruição ambiental. Os padrões de industrialização vigentes principalmente nos países centrais levam ao esgotamento de recursos naturais nãorenováveis, agravando inclusive os problemas sociais - situação chamada por Porto ${ }^{38}$ de crise ambiental contemporânea.

Já Tambellini e Câmara ${ }^{39}$ discutem a incorporação da temática saúde e ambiente no campo da Saúde Coletiva, considerando aspectos históricos, teórico-conceituais e metodológicos da Saúde Ambiental. Para os autores, ela só foi incorporada à Saúde Coletiva quando superou uma concepção moldada na Epidemiologia tradicional, que não levava em conta as questões subjetivas e as explicações das Ciências Sociais. Essa incorporação se deu de forma articulada com a Saúde do Trabalhador, quando esta passou a abranger a relação entre produção, ambiente e saúde. 
A necessidade de articulação entre Saúde Ambiental e Saúde do Trabalhador é evidente quando se observa que "na quase totalidade das vezes as poluições ambientais de grandes proporções têm como principal origem os processos produtivos". ${ }^{39, ~ p . ~} 54$

Assim, para Tambellini e Câmara, ${ }^{39}$ as consequências danosas da relação produçãoambiente-saúde devem ser enfrentadas com ações voltadas para os processos produtivos. Os autores apresentam algumas propostas, das quais destacamos: sistemas de vigilância sobre poluentes e risco; redes de monitoramento de emissões; programas específicos na rede de atendimento à saúde; programas de educação ambiental; avaliações de impacto ambiental da implantação e desenvolvimento das empresas.

Já Porto ${ }^{38}$ destaca a importância de evitar a falsa polarização entre a questão ambiental e as demandas específicas dos movimentos de trabalhadores. Afinal, tanto a saúde de quem trabalha quanto os problemas ambientais são consequências de um modelo de desenvolvimento que concentra renda e poder.

Para enfrentar esse modelo, o autor defende a adoção do paradigma da justiça ambiental, também chamada de ambientalismo popular ou ambientalismo dos pobres, que propõe articular o movimento ambientalista com o enfrentamento as lógicas de colonização e opressão política, econômica e cultural, de forma a resistir aos efeitos nefastos do capitalismo globalizado.

Na base estudada, somente o artigo de Silva et al. ${ }^{40}$ trata especificamente da questão dos agrotóxicos, tão relevante no Brasil. Os autores chamam atenção para o papel do Estado no enorme incremento do uso de agrotóxicos, já que o II Plano Nacional de Desenvolvimento - PND de 1974 vinculava a possibilidade de crédito agrícola à aquisição desses produtos.

Silva et al. ${ }^{40}$ entendem que os agrotóxicos são um dos mais importantes fatores de risco à saúde humana, e lembram que seus efeitos não dizem respeito somente aos trabalhadores expostos, mas à população em geral.

No caso específico dos trabalhadores, os autores defendem que devem ser considerados diversos fatores que influenciam sua exposição: o processo de trabalho; a organização do trabalho; as estratégias de utilização dos agrotóxicos; as estratégias de redução da exposição; a percepção de risco pelos trabalhadores; a classificação dos agrotóxicos, que varia de levemente a extremamente tóxico.

Além dos agrotóxicos, Silva et al. ${ }^{40}$ lembram que o trabalho no setor agrícola está sujeito a diversos outros riscos e danos, tais como: acidentes com ferramentas manuais ou com animais peçonhentos; exposição a agentes infecciosos e parasitários, a radiação solar, a ruído e vibração, a partículas e a fertilizantes; ritmo intenso de trabalho, com cobrança de produtividade. 
ISSN 2179-6750

Assim, os autores afirmam que a agricultura brasileira constitui um quadro bastante desfavorável para a saúde dos trabalhadores do setor, uma vez que tem como pano de fundo a intensa concentração fundiária, o ganho de produtividade, a incorporação tecnológica com grande impacto sobre a saúde e o crescimento das exportações.

Ao se abordar outro extremo do mundo do trabalho, Schulte e Salamanca-Buentello ${ }^{41}$ apresentam as questões que envolvem a presença de nanopartículas nos ambientes de trabalho. Por conta de seu desenvolvimento recente e pouco expressivo se comparado a outros setores, a nanotecnologia ainda não foi estudada o suficiente para que se conheça seus prejuízos à saúde humana.

Assim, os trabalhadores das empresas que lidam com nanopartículas são expostos a possíveis riscos ainda desconhecidos - e os autores rejeitam o argumento de que esses trabalhadores são livres para aceitar essas condições, uma vez que precisam manter seus empregos.

\section{Determinação social ou determinantes sociais da saúde?}

O debate sobre o papel central do trabalho na determinação social da saúde aparece em poucos dos artigos estudados, e nenhum deles se propõe a analisar essa questão em profundidade.

A título de exemplo, Minayo-Gomez e Thedim-Costa ${ }^{20}$ citam a questão da determinação social da saúde apenas em seu parágrafo inicial:

A incorporação das ciências sociais na produção de conhecimentos sobre a relação trabalho-saúde-ambiente adquire um novo enfoque, a partir dos anos 70 do século passado, em decorrência do entendimento do processo saúde-doença introduzido pela Medicina Social LatinoAmericana. Sob o primado das teorias da determinação social, colocouse em foco a relevância do trabalho na reprodução social das populações. ${ }^{20,}$ p. 126 , grifo nosso

Da mesma forma, Sato e Bernardo ${ }^{26}$ somente mencionam a determinação social da saúde como parte da distinção entre a Medicina do Trabalho, a Saúde Ocupacional e a Saúde do Trabalhador:

Se o [discurso] da Saúde Ocupacional/Medicina do Trabalho teve sua emergência o contexto do processo de industrialização brasileira, vindo ao encontro da necessidade de controlar a força de trabalho, sustentando-se em uma visão funcionalista e individualizante, a Saúde do Trabalhador é forjada no contexto do ressurgimento do movimento sindical no Brasil no final da década de 1970 e buscou nas relações de trabalho a determinação do processo saúde. ${ }^{26, \text { p. } 876 \text {, grifo nosso }}$ 
ISSN 2179-6750

Brito $^{33}$ cita o termo ao tratar da epidemiologia de gênero, sem fazer referência direta à questão do trabalho no processo de determinação social:

Para Breilh (1993), a epidemiologia de gênero não se reduz à investigação da morbidade e mortalidade que afetam a mulher, nem aos contrastes estatísticos entre sexos, nem à busca de nexos entre patologias femininas e fatores sociais específicos, por mais importantes que sejam essas análises. As investigações nesse campo, para o autor, devem explicar como as relações de gênero intervêm no processo de determinação de saúde-doença levando em conta que essas relações se modificam historicamente e que têm expressões distintas nos diversos grupos humanos. ${ }^{33, \text { p. } 143 \text {, grifo nosso }}$

Ainda que sem usar o termo determinação social da saúde, a mesma autora aborda a questão mais claramente no início de outro artigo, afirmando que "a saúde é expressão de condições sociais, culturais e históricas das coletividades em que o trabalho desempenha papel crucial". 34, p. 196

Outra formulação que aponta para esse papel central do trabalho na determinação social da saúde aparece em Brito, ${ }^{35}$ ao debater como a Saúde do Trabalhador é tratada como questão específica dentro da Saúde Coletiva, e não como tema de interesse geral. A autora questiona o entendimento segundo o qual "apenas um certo número de problemas, bem delimitados, se associam ao trabalho", de forma que "o processo de trabalho só seria de interesse para a Saúde Coletiva quando a vinculação com os processos patológicos for muito nítida". ${ }^{35, ~ p . ~} 880$

Assim, quando autora reafirma "a necessidade de se integrar o trabalho às análises dos condicionantes e determinantes da saúde da população em geral", 35, p. 880, grifo nosso entendemos que sua defesa está mais próxima da lógica da determinação social da saúde do que do modelo multicausal de determinantes.

Afinal, o papel central que a autora atribui ao trabalho nesse processo fica nítido quando afirma que "na medida em que o trabalho representa uma dimensão fundamental

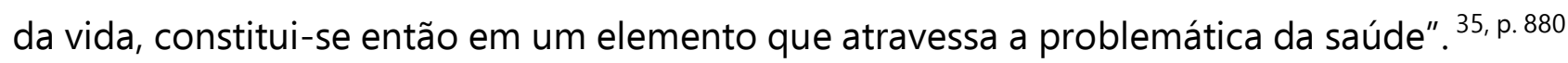

Também sem fazer menção direta à determinação social da saúde, Muntaner ${ }^{42}$ aborda a questão da precarização do trabalho em escala global, e seus reflexos nas condições de vida e de saúde.

Segundo o autor, os trabalhadores da América do Norte e da Europa experimentaram níveis sem precedentes de bem-estar econômico nas décadas que sucederam a Segunda Guerra Mundial, o que configura uma exceção histórica na evolução do capitalismo. Desde a década de 1970, a tendência mundial é a precarização do trabalho, com o consequente declínio das condições de vida de grande parte dos trabalhadores. 
Entre os artigos estudados, o que mais enfatiza o papel central do trabalho na determinação social da saúde é o de Lacaz $_{1}{ }^{17}$ que busca o resgate das formulações originais do campo Saúde do Trabalhador:

Maneira diversa de compreender as relações trabalho e saúde-doença é introduzida pela análise da determinação social do processo saúdedoença, privilegiando o trabalho. A Medicina Social Latino-Americana apreende-o através do processo de trabalho, categoria explicativa que se inscreve nas relações sociais de produção estabelecidas entre capital e trabalho. E, conforme a acepção marxista, aqui o trabalho é, ontologicamente, a ação do homem sobre a natureza para modificá-la e transformá-la e a si mesmo. ${ }^{43, \text { p. } 759 \text {, grifo nosso }}$

Lacaz $^{17}$ afirma ainda que o próprio trabalho e suas diferentes formas de organização, divisão e valorização são características de cada modo de produção e formação social. Assim, o estudo das relações trabalho-saúde e do adoecimento pelo trabalho tem caráter histórico.

O único artigo a utilizar ambos os termos (determinação social da saúde e determinantes sociais da saúde) é o de Alves $^{43}$, sobre Vigilância em Saúde do Trabalhador e Promoção da Saúde. A autora faz referência ao debate sobre o conceito ampliado de saúde, apresentando a crítica à visão tradicional que entende saúde como ausência de doenças ou equilíbrio do organismo.

Segundo a autora, o filósofo e médico francês Canguilhem conceitua a saúde como "a possibilidade de cair enfermo e de poder recuperar-se, [...] como o conjunto dos poderes que nos permitem viver sob a imposição do meio, [...] uma experiência subjetiva vivenciada pelo sujeito". ${ }^{43,}$ p. 320

A partir desse conceito, Alves ${ }^{43}$ defende um novo enfoque para as práticas de promoção a saúde. Vale registrar a ausência de menção ao trabalho, substituído por renda entre os requisitos para a saúde citados pela autora:

Este novo enfoque, que parte de uma concepção ampla do processo saúde-doença, aponta para os determinantes múltiplos da saúde e para a intersetorialidade, afirmando que os requisitos para a saúde são: paz, educação, habitação, alimentação, renda, ecossistema estável, recursos sustentáveis, justiça social e equidade (Buss, 2000). ${ }^{43}$, p. 320, grifo nossos

A seguir, a autora defende a aproximação entre a Vigilância em Saúde do Trabalhador e a Promoção da Saúde. Ao abordar as similaridades entre os dois campos, menciona os conceitos de determinação social e de determinantes sociais como se fossem equivalentes:

Assim como no enfoque da promoção da saúde e da vigilância da saúde enfatiza-se o caráter de multideterminação do processo saúde/doença, 
ISSN 2179-6750

que guarda relação com aspectos econômicos, sociais, políticos e ambientais, a Saúde do Trabalhador e a Vigilância em Saúde do Trabalhador concebem o processo saúde/doença como socialmente determinado ${ }^{44}$. (Laurell, 1987).

Com base nesse conceito ampliado de saúde, [...] a Saúde do Trabalhador elege como seu objeto de estudos não apenas os riscos e os agravos/efeitos para a saúde, mas também os determinantes de tais riscos e efeitos. Esses determinantes, em Saúde do Trabalhador, traduzem-se no conceito de processo de trabalho, que na verdade torna-se o objeto de estudos e intervenção dessa área de atuação e que é responsável por tais riscos e agravos (Almeida, 2000). ${ }^{43}$, p. 321, grifos nossos

Alves $^{43}$ conclui defendendo a ampliação da atuação intersetorial em Saúde do Trabalhador, no sentido do maior diálogo entre os setores governamentais diretamente envolvidos (Ministério da Previdência, Ministério da Saúde e Ministério do Trabalho), assim como na busca de parceria com organizações dos trabalhadores e da sociedade civil.

Por sua vez, a menção a determinantes sociais da saúde aparece com relativa frequência entre os artigos estudados, algumas vezes acompanhado do termo condicionantes, mas também sem maior reflexão.

Um exemplo é o artigo de Sato, ${ }^{23}$ que fala em "diagnosticar as condições de trabalho e saúde para eleger prioridades no sentido de eliminar os determinantes e condicionantes dos problemas de saúde a partir do conhecimento dos trabalhadores". 23, p. 491, grifo nosso

Tambellini e Câmara ${ }^{39}$ mencionam o mesmo termo ao caracterizar as duas funções da Saúde Coletiva, entendida por eles como um campo de práticas teóricas e de intervenção concreta na realidade:

1. A produção de conhecimentos e de tecnologias sobre a saúde e a doença humana e seus determinantes em termos coletivos, tendo por base sua natureza complexa que integra as dimensões do ecológico, do biológico, do social e do psíquico, articulando as experiências e as vivências coletivas do acontecimento "doença".

2. A intervenção concreta na coletividade, no indivíduo ou em qualquer elemento do contexto que compõe o complexo de determinantes e condicionantes dos processos de saúde/doença, tendo por base a produção científica sobre o particular. ${ }^{39, \text { p. 51, grifos }}$ nossos 


\section{Discussão}

A partir dos artigos estudados, verificamos que a produção científica sobre Saúde do Trabalhador constitui importante produção teórica, que abrange diversos aspectos da relação entre trabalho e saúde.

Entre os artigos que abordam a constituição do campo interdisciplinar da Saúde do Trabalhador, destacamos que somente um tratou da relação entre esse campo e o campo mais abrangente da Saúde Coletiva. ${ }^{19}$

Também ressaltamos a pertinência da crítica feita por Minayo-Gomez e Lacaz, ${ }^{21}$ segundo a qual faltam instrumentos que possam compreender a totalidade heterogênea do mundo do trabalho contemporâneo.

Nesse sentido, notamos que, embora seja efetivamente plural e interdisciplinar, o campo da Saúde do Trabalhador tem dialogado pouco com a Sociologia do Trabalho e com outras áreas do conhecimento que podem contribuir para essa compreensão mais abrangente.

Uma exceção significativa são os artigos sobre gênero: destacamos essa categoria não apenas pela relevância do tema, mas também porque são os artigos que buscam uma compreensão histórica, articulando os processos de divisão sexual do trabalho de divisão social do trabalho. Chama a atenção o fato de esse debate aparecer com maior profundidade no primeiro artigo em ordem cronológica, de Brito e D'Acri. ${ }^{31}$

Por outro lado, ressaltamos que nenhum dos artigos estudados abordou com profundidade um aspecto que consideramos tão relevante quanto a questão do gênero para compreender o mundo do trabalho no Brasil: a imensa desigualdade racial, consequência de um passado escravista ${ }^{45}$ ainda muito recente em termos históricos.

Já os autores que debatem a relação entre Saúde Ambiental e Saúde do Trabalhador apontam para os processos produtivos como causadores de consequências danosas para a saúde de quem trabalha e da população em geral. O debate considera processos históricos e aponta tendências da globalização movida pela racionalidade econômica do capital, mas nos parece limitado ao propor soluções.

A título de exemplo, Silva et al. ${ }^{40}$ propõem uma abordagem intersetorial e interdisciplinar, em diálogo aberto e contínuo entre Estado, empresas, trabalhadores e organizações não-governamentais, no sentido de promover a produção segura, em que "o processo de trabalho deve produzir, igualmente bem, produtos e saúde". ${ }^{40, ~ p . ~} 31$ Consideramos que essa proposta não leva em conta a existência de interesses antagônicos entre capital e trabalho, pois bastaria o diálogo entre ambos para chegar à produção segura. 
ISSN 2179-6750

Embora nenhum dos artigos tenha abordado em profundidade o tema da determinação social da saúde, destacamos essa categoria justamente para assinalar o que consideramos a maior lacuna teórica do material estudado.

Afinal, entendemos que a determinação social da saúde está diretamente relacionada com a centralidade do trabalho: em uma sociedade capitalista, na qual a grande maioria das pessoas depende da venda de sua força de trabalho para sobreviver, a saúde é fortemente influenciada pelo desgaste decorrente desse trabalho e pela capacidade de adquirir bens e serviços essenciais à saúde - que também depende das condições de venda de sua força de trabalho.

Assim, ao constatarmos que o debate teórico sobre Saúde do Trabalhador pouco aborda a determinação social da saúde (e muitas vezes trata apenas dos determinantes sociais da saúde, considerando o trabalho ou a renda como mais um entre eles), entendemos que a Saúde do Trabalhador deixa de reivindicar a centralidade do trabalho.

\section{Conclusão}

Identificamos um relevante debate sobre a constituição do campo interdisciplinar denominado Saúde do Trabalhador - mas verificamos que foi pouco abordada a relação entre ele e o campo mais abrangente da Saúde Coletiva. Considera-se importante afirmar que faltam instrumentos que possam compreender a totalidade heterogênea do mundo do trabalho contemporâneo.

Verificamos que os artigos sobre gênero são os que mais buscam uma compreensão histórica, articulando os processos de divisão sexual do trabalho e divisão social do trabalho. Por outro lado, notamos a ausência de menções à desigualdade racial, muito relevante no mundo do trabalho no Brasil.

Constatamos que os artigos sobre a questão ambiental apontam para a racionalidade econômica do capital, que causa danos à saúde dos trabalhadores e ao ambiente. Porém, verificamos que esse diagnóstico é acompanhado de propostas que não levam em conta os interesses antagônicos entre capital e trabalho, como se bastasse um diálogo amplo e intersetorial para que a produção se tornasse segura.

Destacamos também o debate sobre a determinação social da saúde, que aparece pouco na base estudada, ao mesmo tempo em que muitos artigos adotam o termo determinantes sociais sem maior reflexão. Entendemos que a Saúde Coletiva deixa de reividincar a centralidade do trabalho quando se afasta da teoria da determinação social da saúde. 
No mesmo sentido, embora diversos artigos mencionem a categoria processo de trabalho, há poucas referências à obra de Marx e aos autores da Sociologia do Trabalho. Entendemos que esse referencial teórico pode contribuir de forma significativa para a compreensão da questão do trabalho em uma perspectiva emancipatória.

\section{Contribuição autoral}

O autor FMC participou da concepção, planejamento, análise, interpretação e redação do trabalho; e, o autor AM participou na interpretação e redação do trabalho. Ambos/todos os autores aprovaram a versão final encaminhada.

\section{Referências}

1. Druck G. A precarização social do trabalho no Brasil. In: Antunes R, organizador Riqueza e miséria do trabalho no Brasil II. São Paulo: Boitempo; 2013. p. 55-74.

2. Oliveira ACO, Soares M. Superexploração da força de trabalho e as condições de trabalho na pandemia: conservadorismo e a questão étnico-racial. In: Sousa AAS, Oliveira ACO, Silva LB, Soares M, organizadores. Trabalho e os limites do capitalismo: novas facetas do neoliberalismo. Uberlândia: Navegando Publicações; 2020. p. 105-30.

3. Druck G. A terceirização na saúde pública: formas diversas de precarização do trabalho. Trab Educ Saude. 2016;14(Suppl 1):14(Suppl):15-43. https://doi.org/10.1590/1981-7746sol00023.

4. Cegatti F, Carnut L, Mendes Á. Terceirizações na área da saúde no Brasil: reflexos no SUS, nas políticas sociais e nos trabalhadores. J Manag PrimHealth Care. 2020;12:e36. https://doi.org/10.14295/jmphc.v12.978.

5. Mendes Á, Carnut L. Capital, estado, crise e a saúde pública brasileira: golpe e desfinanciamento. SER Soc. 2020;22(46):9-32. https://doi.org/10.26512/ser_social.v22i46.25260.

6. Schraiber LB. Saúde coletiva: um campo vivo. In: Paim JS. Reforma sanitária brasileira: contribuição para a compreensão e crítica. Salvador: Edufba; 2008. Prefácio, p. 9-19.

7. Campos GWS. Saúde pública e saúde coletiva: campo e núcleo de saberes e práticas. Cien Saúde Colet. 2020;5(2);219-230. https://doi.org/10.1590/S1413-81232000000200002

8. Paim JS. Reforma sanitária brasileira: contribuição para a compreensão e crítica. Salvador: Edufba; 2008. 
9. Mendes Á, Carnut L. Crise do capital, estado e neofascismo: Bolsonaro, saúde pública e atenção primária. Rev Soc Bras Econ Polit. 2020 [citado 202109 02];(57):174-210. Disponível em: https://www.revistasep.org.br/index.php/SEP/article/view/636

10. Dantas AV. Do socialismo à democracia: dilemas da classe trabalhadora no Brasil recente e o lugar da Reforma Sanitária Brasileira. Rio de Janeiro: UFRJ; 2014.

11. Silva TH. Entre o consenso e o Minotauro da saúde: um balanço da estratégia da reforma sanitária brasileira. In: Fleury S, organizador. Teoria da reforma sanitária: diálogos críticos. Rio de Janeiro: Editora Fiocruz; 2018. p. 291-336.

12. Packer AL. Indicadores de centralidade nacional da pesquisa comunicada pelos periódicos de saúde coletiva editados no Brasil. Cien Saude Colet. 2015;20(7):1983-95. https://doi.org/10.1590/1413-81232015207.07122015.

13. Lacaz FAC. Saúde dos trabalhadores: cenário e desafios. Cad Saude Publica. 1997;13(suppl 2):S07-19. https://doi.org/10.1590/S0102-311X1997000600002.

14. Ministério da Saúde (BR). Portaria n. 1.823, de 23 de agosto de 2012. Institui a política nacional de saúde do trabalhador e da trabalhadora. Brasília, DF: MS; 2012 [acesso 2 set. 2021]. Disponível em: http://bvsms.saude.gov.br/bvs/saudelegis/gm/2012/prt1823_23_08_2012.html

15. Deppe H-U. Novas técnicas, medicina do trabalho e saúde. Cad Saude Publica. 1990;6(4):422-43. https://doi.org/10.1590/S0102-311X1990000400005.

16. Minayo-Gomez C, Thedim-Costa SMF. A construção do campo da saúde do trabalhador: percurso e dilemas. Cad Saude Publica. 1997;13(suppl 2): 21-32. https://doi.org/10.1590/S0102-311X1997000600003.

17. Lacaz FAC. O campo saúde do trabalhador: resgatando conhecimentos e práticas sobre as relações trabalho-saúde. Cad Saude Publica. 2007;23(4):757-66. https://doi.org/10.1590/S0102-311X2007000400003.

18. Laurell AC, Noriega M. Processo de produção e saúde: trabalho e desgaste operário. São Paulo: Hucitec; 1989.

19. Porto MFS, Almeida GES. Significados e limites das estratégias de integração disciplinar: uma reflexão sobre as contribuições da saúde do trabalhador. Cien Saude Colet. 2002;7(2):335-47. https://doi.org/10.1590/S1413-81232002000200013.

20. Minayo-Gomez C, Thedim-Costa SMF. Incorporação das ciências sociais na produção de 
conhecimentos sobre trabalho e saúde. Cien Saude Colet. 2003;8(1):125-36. https://doi.org/10.1590/S1413-81232003000100010.

21. Minayo-Gomez C, Lacaz FAC. Saúde do trabalhador: novas-velhas questões. Cien Saude Colet. 2005;10(4):797-807. https://doi.org/10.1590/S1413-81232005000400002.

22. Mendes R. Produção científica brasileira sobre saúde e trabalho, publicada na forma de Dissertações de Mestrado e Teses de Doutorado, 1950-2002. Rev Bras Med Trab.2003;1(2):87-118.

23. Sato L. As implicações do conhecimento prático para a vigilância em saúde do trabalhador. Cad Saude Publica. 1996;12(4):489-95. https://doi.org/10.1590/S0102$311 \times 1996000400007$.

24. Sato L. Prevenção de agravos à saúde do trabalhador: replanejando o trabalho através das negociações cotidianas. Cad Saude Publica. 2002;18(5):1147-66. https://doi.org/10.1590/S0102-311X2002000500002.

25. Sato L. LER: objeto e pretexto para a construção do campo trabalho e saúde. Cad Saude Publica. 2001;17(1):147-52.

26. Sato L, Bernardo MH. Saúde mental e trabalho: os problemas que persistem. Cien Saude Colet. 2005;10(4): 869-78. https://doi.org/10.1590/S1413-81232005000400011.

27. Leão LHC, Minayo-Gomez C. A questão da saúde mental na vigilância em saúde do trabalhador. Cien Saude Colet. 2014;19(12):4649-58. https://doi.org/10.1590/1413812320141912.12732014.

28. Brant LC, Minayo-Gomez C. A transformação do sofrimento em adoecimento: do nascimento da clínica à psicodinâmica do trabalho. Cien Saude Colet. 2004;9(1): 213-23. https://doi.org/10.1590/S1413-81232004000100021.

29. Freire PA. Assédio moral e saúde do trabalhador. Trab Educ Saude. 2008;6(2):367-80. https://doi.org/10.1590/S1981-77462008000200009.

30. Ramminger T, Athayde MRC, Brito J. Ampliando o diálogo entre trabalhadores e profissionais de pesquisa: alguns métodos de pesquisa-intervenção para o campo da saúde do trabalhador. Cien Saude Colet. 2013;18(11):3191-202. https://doi.org/10.1590/S1413-81232013001100010.

31. Brito JC, D'Acri V. Referencial de análise para o Estudo da relação trabalho, mulher e saúde. Cad Saude Publica. 1991;7(2):201-14. https://doi.org/10.1590/S0102- 
$311 \times 1991000200006$.

32. Aquino EML, Menezes GMS, Marinho LFB. Mulher, saúde e trabalho no Brasil: desafios para um novo agir. Cad Saude Publica. 1995;11(2):281-90. https://doi.org/10.1590/S0102-311X1995000200012.

33. Brito JC. Uma proposta de vigilância em saúde do trabalhador com a ótica de gênero. Cad Saude Publica. 1997;13(suppl 2):141-4. https://doi.org/10.1590/S0102$311 \times 1997000600013$.

34. Brito JC. Enfoque de gênero e relação saúde/trabalho no contexto de reestruturação produtiva e precarização do trabalho. Cad Saude Publica.2000;16(1):195-204. https://doi.org/10.1590/S0102-311X2000000100020.

35. Brito JC. Trabalho e saúde coletiva: o ponto de vista da atividade e das relações de gênero. Cien Saude Colet. 2005;10(4):879-90. https://doi.org/10.1590/S141381232005000400012.

36. Franco T, Druck G. Padrões de industrialização, riscos e meio ambiente. Cien Saude Colet. 1998;3(2):61-72. https://doi.org/10.1590/S1413-81231998000200006.

37. Porto MFS, Freitas CM. Análise de riscos tecnológicos ambientais: perspectivas para o campo da saúde do trabalhador. Cad Saude Publica. 1997;13(suppl 2):59-72. https://doi.org/10.1590/S0102-311X1997000600006.

38. Porto MFS. Saúde do trabalhador e o desafio ambiental: contribuições do enfoque ecossocial, da ecologia política e do movimento pela justiça ambiental. Cien Saede Colet. 2005;10(4):829-38. https://doi.org/10.1590/S1413-81232005000400008.

39. Tambellini AT, Câmara VM. A temática saúde e ambiente no processo de desenvolvimento do campo da saúde coletiva: aspectos históricos, conceituais e metodológicos. Cien Saude Colet. 1998;3(2):47-59. https://doi.org/10.1590/S141381231998000200005.

40. Silva JM, Novato-Silva E, Faria HP, Pinheiro TMM. Agrotóxico e trabalho: uma combinação perigosa para a saúde do trabalhador rural. Cien Saude Colet. 2005;10(4):891-903. https://doi.org/10.1590/S1413-81232005000400013.

41. Schulte PA, Salamanca-Buentello F. Ethical and scientific issues of nanotechnology in the workplace. Cien Saude Colet. 2007;12(5):1319-32. https://doi.org/10.1590/S141381232007000500030. 
ISSN 2179-6750

42. Muntaner C. Global precarious employment and health inequalities: working conditions, social class, or precariat? Cade Saude Publica. 2016;32(6):e00162215. https://doi.org/10.1590/0102-311X00162215.

43. Alves RB. Vigilância em saúde do trabalhador e promoção da saúde: aproximações possíveis e desafios. Cad Saude Publica. 2003;19(1):319-22. https://doi.org/10.1590/S0102-311X2003000100036.

44. Laurell AC, Noriega M, organizadores. Processo de Produção e Saúde. São Paulo: Editora Hucitec; 1987. Para o estudo da saúde na sua relação com o processo de trabalho. p. 99137.

45. Ianni O. A ideia do Brasil moderno. São Paulo: Brasiliense, 2004.

Francisco Mogadouro da Cunha | https://orcid.org/0000-0003-1374-1951

http://lattes.cnpq.br/2592886005091096

Áquilas Mendes | https://orcid.org/ 0000000256324333

http://lattes.cnpq.br/7310723011915165 